\title{
Distrações e interrupções no preparo e na administração de medicamentos em unidades de internação hospitalar
}

\author{
Distractions and interruptions in medication preparation and \\ administration in inpatient units
}

Weslen Carlos Junior de Freitas ${ }^{1}$, Vanessa Cristina Alves ${ }^{1}$, Jeferson Silva Ramos ${ }^{1}$,

Samantha Rodrigues Garbis Chagas' ${ }^{1}$, Luciana Regina Ferreira da Mata²,

Aline Carrilho Menezes ${ }^{1}$, Helen Cristiny Teodoro Couto Ribeiro ${ }^{1}$

\section{RESUMO}

Objetivou-se identificar as distraçôes e as interrupçôes durante o preparo e a administração de medicamentos pela equipe de enfermagem em unidades de internaçáo médico-cirúrgica. Trata-se de estudo quantitativo, do tipo transversal com técnica de observação sistemática para a coleta de dados. Observou-se 342 preparos e 364 administraçóes de medicamentos. Foram identificadas 252 distraçóes, a maioria ocorreu durante o preparo de medicamentos, esteve relacionado à conversa paralela e a equipe de enfermagem foi a maior fonte. As interrupçôes ocorreram em 111 momentos, semelhantemente às distraçôes ocorreram em sua maioria no preparo dos medicamentos, a conversa paralela foi a principal causa e foi iniciada por terceiros (profissionais da equipe de enfermagem e outros, pacientes e acompanhantes). Tais eventos interferem na segurança do paciente e na qualidade do ambiente de trabalho, importantes de se abordar nos currículos dos cursos dos profissionais de saúde e no planejamento estratégico das instituições de saúde.

Descritores: Segurança do Paciente; Enfermagem; Erros de Medicação.

\section{ABSTRACT}

The objective was to identify distractions and interruptions during medication preparation and administration by the nursing staff in medical-surgical inpatient units. This is a quantitative, cross-sectional study in which the systematic observation technique was used for data collection. In total, were observed 342 preparations and 364 administrations of medication, with identification of 252 distractions that occurred mostly during drug preparation, related to parallel conversation, and the nursing staff was the largest source. Interruptions occurred in 111 moments, mostly during medication preparation, parallel conversation was the main cause and initiated by third parties (professionals of the nursing team and others, patients and caregivers). Such events interfere with patient safety and the quality of the work environment. It is important to address this topic in the curriculum of health professionals' courses and in the strategic planning of health institutions.

Descriptors: Patient Safety; Nursing; Medication Errors.

\footnotetext{
${ }^{1}$ Universidade Federal de São João del-Rei — Divinópolis (MG), Brasil. E-mails: weslen.ufsj@hotmail.com, vanessaalvescapelini@yahoo.com.br, jefersonsilvaramos@hotmail.com, samanthagarbisdivi@gmail.com, alinecarrilhomenezes@gmail.com, helen.cristiny@ufsj.edu.br ${ }^{2}$ Universidade Federal de Minas Gerais — Belo Horizonte (MG), Brasil. E-mail: lucianarfmata@gmail.com
}

Como citar este artigo: Freitas WCJ, Alves VC, Ramos JS, Chagas SRG, Mata LRF, Menezes AC, et al. Distrações e interrupções no preparo e na administração de medicamentos em unidades de internação hospitalar. Rev. Eletr. Enferm. [Internet]. 2019 [acesso em: ];21:53621. Disponível em: https://doi.org/10.5216/ree.v21.53621. 


\section{INTRODUÇÃO}

A segurança do paciente é uma das dimensôes da assistência à saúde com qualidade. O relatório To Err Is Human: Building a Safer Health System do Instituto de Medicina (IOM) dos Estados Unidos da América (EUA) revelou que, aproximadamente, 100.000 pessoas morriam todos os anos nos EUA em consequência de iatrogenias ${ }^{(1)}$. Em 2004 a Organização Mundial da Saúde (OMS) lançou a Aliança Mundial para a segurança do paciente, com o intuito de aumentar o envolvimento político nas boas práticas assistenciais nos serviços de saúde.

No Brasil, o Ministério da Saúde instituiu o Programa Nacional de Segurança do Paciente (PNSP) com açóes obrigatórias para a promoção da segurança do paciente e melhoria da qualidade ${ }^{(2)}$. Dentre as açóes há aquelas voltadas especificamente para a segurança no sistema de medicação.

O terceiro Desafio Global da OMS "Medication Without Harm" propóe reduzir 50\% dos danos evitáveis relacionados aos medicamentos em todo o mundo até $2022^{(3)}$. A Classificação Internacional de Segurança do Paciente define erro como a falha na execução de uma ação que foi planejada ou o desenvolvimento incorreto de um plano ${ }^{(4)}$. Entre os erros ocorridos com pacientes em instituiçôes de saúde, estima-se que o erro de medicação (EM) atinge anualmente sete milhóes de pacientes no mundo(5).

A administração de medicamentos é um processo complexo e multidisciplinar. Os médicos prescrevem, os farmacêuticos dispensam e a enfermagem possui a responsabilidade primária pela administração ${ }^{(6)}$. O EM pode ocorrer em qualquer uma destas fases, sendo essencial melhorar o sistema de medicação e criar estratégias para minimizar os $\mathrm{EM}^{(7,8)}$.

As principais causas de EM são a sobrecarga de trabalho, a fadiga, a má impressão de rótulos dos medicamentos, a aplicação incorreta dos 10 certos para medicação, a ilegibilidade das prescriçóes e as distraçóes e interrupçóes ${ }^{(8,9)}$. As distraçóes e as interrupçóes rompem o foco e a concentração do profissional no exercício de alguma atividade. Os profissionais expostos a interrupçóes estão mais susceptíveis a erros. A ocorrência de interrupçóes está relacionada com o aumento e gravidade de $\operatorname{EM}^{(9)}$

Em muitos estudos os termos distração e interrupção são utilizados como sinônimos ${ }^{(10)}$. No presente estudo, distração é o comportamento observado ao desviar a atenção na execução de uma tarefa primária, ou em situaçóes de respostas verbais a uma tarefa secundária associada ou não à atividade em execução, sem interromper a atividade primária. Por exemplo, desviar a atenção rapidamente para observar quem entra ou sai do posto de enfermagem durante o preparo de medicamentos. A auto distraçáo foi considerada o evento de desvio da atenção provocada pelo próprio profissional, como o início de uma conversa com o colega ou paciente durante o preparo ou administração de medicamentos.
Já o conceito de interrupção utilizado foi a ruptura da tarefa principal, considerada interna ou externa. As interrupçóes externas podem ser por um colega de trabalho ou pelo paciente/familiar que necessita de ajuda em uma tarefa secundária, implicando na interrupção do preparo ou administração de medicamentos ${ }^{(5)}$. Uma interrupção interna ou auto interrupção é auto induzida (do próprio indivíduo) e ocorre quando o profissional, por escolha pessoal, interrompe a tarefa primária para realizar uma tarefa secundária, não concluindo assim a tarefa principal(5). Para exemplificar, o atendimento ao telefone institucional ou o próprio celular.

A natureza e as consequências das distraçóes e das interrupçóes sobre o processo de trabalho da enfermagem não tem sido muito discutido na literatura, havendo uma lacuna de conhecimento sobre esta temática no Brasil. A investigação dos eventos de distração e interrupção proporciona melhoria na qualidade dos serviços prestados, subsidia a criação de ferramentas para o gerenciamento do EM e coopera para a segurança de todos os envolvidos no processo ${ }^{(11)}$.

Além disso, a partir dos achados destes estudos os programas de formação educacional em enfermagem poderão redirecionar os métodos pedagógicos utilizados no processo de formação de futuros profissionais de saúde em relação ao gerenciamento dos EM. A incorporação de habilidades sobre o gerenciamento de interrupçáo nos currículos tem sido recomendada na literatura científica ${ }^{(5)}$.

Ademais, estudos que tenham o objetivo de identificar distraçôes e interrupçôes na administração de medicamentos justificam-se porque o conhecimento dos profissionais de saúde sobre a temática pode aumentar a conscientização sobre a dinâmica do problema e proporcionar mudanças comportamentais $^{(5)}$.

Neste sentido, questiona-se: como se configura as distrações e as interrupções durante o processo de preparo e administraçáo de medicamentos pela equipe de enfermagem em unidades de internação médico-cirúrgica? Assim, o objetivo desta pesquisa foi identificar as distraçóes e as interrupçôes durante o preparo e a administração de medicamentos pela equipe de enfermagem em unidades de internação médico-cirúrgica.

\section{MÉTODO}

Trata-se de um estudo descritivo, com abordagem quantitativa do tipo transversal, realizado por meio de observação sistemática. Foi realizado em duas unidades de internação de um hospital geral do interior de Minas Gerais/ Brasil. As unidades de internação são para adultos e atendem pacientes clínicos e cirúrgicos em cuidados intermediários e semi-intensivos da rede privada e suplementar. A instituiçáo possui 400 leitos e presta assistência a uma população de aproximadamente 1.220 .000 habitantes. A escolha deste 
cenário justifica-se por serem unidades de ensino clínico de acadêmicos de enfermagem da instituição proponente do estudo, onde a administração de medicamentos é uma das ações mais frequentes, o que torna relevante a descrição da realidade para futuras intervençóes.

Foram considerados todos os 28 profissionais que compóem a equipe de enfermagem das unidades em estudo como potenciais participantes da pesquisa, onde 20 concordaram em participar. No entanto, durante a coleta de dados, houve duas transferências de setor e oito profissionais não desempenharam a função de preparo ou administração de medicamentos. Assim, a amostra foi constituída de 10 profissionais de enfermagem. Os critérios de inclusão para participação na pesquisa foram: ser profissional de enfermagem, prestar assistência direta ao paciente e atuar no setor há no mínimo três meses. Foram excluídos os profissionais em férias ou qualquer tipo de afastamento durante o período de coleta de dados.

A coleta de dados foi realizada em três fases no período de dezembro de 2016 e junho de 2017. Na primeira fase realizou-se o recrutamento dos profissionais por meio de uma reuniáo com toda a equipe de enfermagem, apresentados os objetivos e a justificativa da pesquisa e, posteriormente, o convite para participação. Para tanto, os que aceitaram assinaram o Termo de Consentimento Livre e Esclarecido (TCLE) e responderam um questionário referente aos dados sociodemográficos (idade, estado civil, escolaridade, tempo de formação e atuação na instituição nas unidades de internação). A segunda fase contemplou o treinamento da equipe de pesquisadores e a aplicação do pré-teste, com o intuito de aperfeiçoar o instrumento de coleta de dados elaborado a partir de dados da literatura ${ }^{(12)}$.

$\mathrm{Na}$ terceira fase foi utilizado o referido instrumento, o qual foi estruturado com dados de identificação da observação (data, horário, setor da coleta); questóes para caracterizar as distraçóes e as interrupçóes, a saber, em relaçáo à origem (auto distração, auto interrupção, originado por profissionais, pacientes ou acompanhantes), ao motivo da interrupção/distração (uso de telefone da instituição ou pessoal, sobreposição de tarefas, falta de medicamentos ou material, conversa paralela, ruídos no ambiente, instrução de outros profissionais ou alunos) e se o profissional permitiu a distração ou interrupção durante o preparo e a administração dos medicamentos. Mensurou-se a duração da distração e da interrupçáo por meio de cronômetro. Para tanto, devido à rapidez de ocorrência dos eventos foram estabelecidos três períodos de observação: menor que um minuto; de um a três minutos; e, maior que três minutos.

A unidade de observação foi considerada como cada episódio de preparo e de administração de medicamentos. Foi incluído todas as vias de administração de medicamentos. A equipe de pesquisadores foi constituída por uma docente e cinco acadêmicos devidamente treinados.
Cada pesquisador observava um profissional de cada vez nos horários intencionalmente escolhidos pela disponibilidade dos pesquisadores de 11, 14 e 17 horas. O pesquisador se posicionava no posto de enfermagem para o registro da observação do preparo dos medicamentos e, em seguida, o pesquisador seguia com o profissional até as enfermarias para a observaçáo da administraçáo dos medicamentos. Por vezes, o pesquisador interrompia a observação na etapa de preparo porque o profissional que preparava não dada seguimento na administraçáo dos medicamentos. Este acompanhamento foi realizado de forma silenciosa para que não houvesse interferência no processo de preparo e administração dos medicamentos.

A permanência do observador nas enfermarias, durante a realização do convite aos participantes e no pré-teste, contribuiu para diminuir o efeito Hawthorne (mudança de comportamento quando se é observado), pois os pesquisadores passaram a fazer parte do contexto e os profissionais começaram a vê-los como integrantes da equipe ${ }^{(13)}$. Os dados foram processados em planilhas do Excel $^{\circledR}$ versão 2016 para realização das análises descritivas referentes à frequência absoluta, à relativa e à média.

O projeto foi aprovado pelo Comitê de Ética em Pesquisa da instituição proponente e pela instituição-cenário deste estudo, sob parecer $\mathrm{n}^{\circ}$ 1.885.341 e CAAE $\mathrm{n}^{\circ}$ 58517316.4.3001.5130.

\section{RESULTADOS}

Dos 10 profissionais de enfermagem observados, a maioria era do sexo feminino e técnico de enfermagem. A idade média dos profissionais foi de 31,7 anos e a metade relataram ser casados. $\mathrm{O}$ tempo médio de trabalho na área de enfermagem foi de 5,2 anos variando entre seis meses a 18 anos. $\mathrm{O}$ tempo de trabalho na instituição foi em média de 2,2 anos variando entre sete meses a seis anos. O tempo médio de trabalho nas unidades de internação em que a coleta foi desenvolvida foi de dois anos, variando entre sete meses a seis anos (Tabela 1).

A duração total de observaçóes foi de 1.469 minutos e o tempo médio de observação de 146,9 minutos por profissional. Observou-se o preparo de 342 e a administração de 364 medicamentos, nas quais foram registradas 252 situaçóes de distração e 111 de interrupçóes. A média de pacientes por profissional foi de 5,5 .

Das 252 situaçóes de distração, 69,0\% ocorreram durante o preparo e $31,0 \%$ durante a administração dos medicamentos. $\mathrm{O}$ principal motivo das distraçóes relacionou-se à conversa paralela e foi originada a partir de terceiros, sendo que os demais profissionais da equipe de enfermagem foram os que mais causaram distraçóes naqueles que estavam realizando o preparo ou a administração dos medicamentos (Tabela 2).

As interrupçóes ocorreram em 111 momentos, 64,0\% durante o preparo e $36,0 \%$ durante a administração. 
A conversa paralela, assim como nas situaçóes de distração, foi a principal fonte geradora das interrupçóes. A maioria das interrupçóes ocorreu por terceiros (profissionais da equipe de enfermagem, pacientes, acompanhantes e demais profissionais) (Tabela 3).

Tabela 1. Características sociodemográficas dos profissionais observados durante os processos de preparo e administração de medicações $(n=10)$. Minas Gerais, Brasil, 2017.

\section{Características}

ก

$\%$

\section{Sexo}

\begin{tabular}{|c|c|c|}
\hline Masculino & 2 & 20,0 \\
\hline Feminino & 8 & 80,0 \\
\hline \multicolumn{3}{|l|}{ Categoria Profissional } \\
\hline Enfermeiro & 3 & 30,0 \\
\hline Técnico de Enfermagem & 4 & 40,0 \\
\hline Auxiliar de Enfermagem & 3 & 30,0 \\
\hline \multicolumn{3}{|l|}{ Idade (em anos) } \\
\hline 20 a 25 & 1 & 10,0 \\
\hline 26 a 30 & 4 & 40,0 \\
\hline 31 a 35 & 1 & 10,0 \\
\hline 36 a 40 & 4 & 40,0 \\
\hline
\end{tabular}

Tempo de formação

\begin{tabular}{l|l|l}
\hline$<1$ ano & 1 & 10,0 \\
\hline la 5 anos & 6 & 60,0 \\
\hline 5 a 10 anos & 2 & 20,0 \\
\hline$>10$ anos & 1 & 10,0 \\
\hline
\end{tabular}

Tempo de atuação na área

\begin{tabular}{l|c|c}
\hline$<1$ ano & 2 & 20,0 \\
\hline l a 5 anos & 5 & 50,0 \\
\hline 5 a 10 anos & 2 & 20,0 \\
\hline >10 anos & 1 & 10,0 \\
\hline \multicolumn{3}{|l}{} \\
\hline Tempo de trabalho na instituição & 3 & 30,0 \\
\hline$<1$ ano & 6 & 60,0 \\
\hline l a 5 anos & 1 & 10,0 \\
\hline 5 a 10 anos & 0 & 0,0 \\
\hline >10 anos & \multicolumn{2}{|l}{} \\
\hline Tempo de trabalho no setor & 3 & 30,0 \\
\hline$<1$ ano & 6 & 60,0 \\
\hline l a 5 anos & 1 & 10,0 \\
\hline 5 a 10 anos & 0 & 0,0 \\
\hline >10 anos & \multicolumn{3}{|c}{}
\end{tabular}

Tabela 2. Motivos e origem das distrações no preparo e na administração de medicamentos. Minas Gerais, Brasil, 2017.

\begin{tabular}{|c|c|c|}
\hline Distrações & $\mathbf{n}$ & $\%$ \\
\hline \multicolumn{3}{|l|}{ Motivo das Distrações } \\
\hline Conversa paralela & 196 & 77,8 \\
\hline $\begin{array}{l}\text { Ruídos no ambiente (alarmes } \\
\text { sonoros, som de telefones e } \\
\text { conversas entre as pessoas) }\end{array}$ & 23 & 9,1 \\
\hline $\begin{array}{l}\text { Consulta ao prontuário } \\
\text { e/ou prescrição médica }\end{array}$ & 20 & 7,9 \\
\hline $\begin{array}{l}\text { Instrução de outros } \\
\text { profissionais ou alunos }\end{array}$ & 13 & 5,2 \\
\hline Total & 252 & 100,0 \\
\hline \multicolumn{3}{|l|}{ Origem das Distrações } \\
\hline Profissionais de enfermagem & 94 & 37,3 \\
\hline Outros profissionais & 45 & 17,9 \\
\hline Auto distração & 44 & 17,5 \\
\hline Acompanhantes & 39 & 15,5 \\
\hline Pacientes & 30 & 11,9 \\
\hline Total & 252 & 100,0 \\
\hline
\end{tabular}

Tabela 3. Motivos e origem das interrupções no preparo e na administração de medicamentos. Minas Gerais, Brasil, 2017.

\begin{tabular}{l|c|c}
\hline \multicolumn{2}{l|}{$\begin{array}{l}\text { Interrupções } \\
\text { Motivo das Interrupções }\end{array}$} & $\%$ \\
\hline \multicolumn{1}{|c|}{ Conversa paralela } & 52 & 46,8 \\
\hline $\begin{array}{l}\text { Consulta ao prontuário } \\
\text { e/ou prescrição médica }\end{array}$ & 20 & 18,0 \\
\hline Sobreposição de tarefas & 9 & 8,2 \\
\hline $\begin{array}{l}\text { Instrução de outros } \\
\text { profissionais ou alunos }\end{array}$ & 8 & 7,2 \\
\hline Falta de material & 8 & 7,2 \\
\hline $\begin{array}{l}\text { Ruídos no ambiente } \\
\text { (alarmes sonoros) }\end{array}$ & 5 & 4,5 \\
\hline Falta de medicamentos & 5 & 4,5 \\
\hline Atender telefone da instituição & 3 & 2,7 \\
\hline Atender ou usar telefone pessoal & 1 & 0,9 \\
\hline Total & 111 & 100,0 \\
\hline Origem das Interrupções & 46 & 41,4 \\
\hline Auto interrupção & 22 & 19,8 \\
\hline Profissionais de enfermagem & 16 & 14,4 \\
\hline Outros profissionais & 14 & 12,6 \\
\hline Acompanhantes & 13 & 11,7 \\
\hline Pacientes & 111 & 100,0 \\
\hline Total &
\end{tabular}




\section{DISCUSSÃO}

Os participantes do estudo possuem características sociodemográficas similares aos profissionais de enfermagem descritos em outro estudo, quanto à predominância do gênero feminino, à idade, à escolaridade e ao tempo de formação ${ }^{(14)}$.

O número de observaçóes no presente estudo foi superior a um estudo realizado na Alemanha, no qual as observaçóes duraram 524 minutos $^{(15)}$. No entanto, os pesquisadores conseguiram observar mais preparos, foram 431 medicamentos. A diferença no número de preparos e administraçóes de medicamentos observados por participante nesta pesquisa foi devido à ocorrência de fragmentação do processo. O profissional observado durante o preparo nem sempre seguia para a etapa de administração, assim o pesquisador não prosseguia com a observação. Tal fragmentação pode facilitar a ocorrência de erros, pois o profissional que administra um medicamento já diluído não consegue identificar se o preparo ocorreu de forma correta.

Encontrou-se 252 situações de distração no preparo e na administração de medicamentos. Em Barcelona, estudo realizado em uma Unidade de Terapia Intensiva (UTI) neonatal encontrou como fator predominante dos EM a distração da equipe de enfermagem ${ }^{(16)}$. Um estudo na Noruega apontou que as situações de distraçóes afetaram 20,5\% da assistência ao paciente ${ }^{(7)}$.

Encontrou-se também 111 situações de interrupção nesta pesquisa. Outro estudo brasileiro realizado em uma UTI adulto, após 99 horas de observação de 739 atividades, identificou 46,82\% interrupçóes, o que corresponde a 7,85 interrupçóes por hora ${ }^{(17)}$. Um estudo turco mostrou que pelo menos uma interrupçáo ocorreu durante o preparo de medicamentos em 95,9\% das observaçóes realizadas ${ }^{(18)}$.

A conversa paralela foi o principal motivo de distraçóes e de interrupçóes. Estudo internacional concluiu que na maioria das vezes a informação transmitida é irrelevante para o contexto das atividades em execução ${ }^{(19)}$.

Os ruídos sonoros no ambiente corresponderam à segunda causa de distração e a quinta causa de interrupção neste estudo. Uma revisão de literatura internacional identificou os ruídos dos alarmes sonoros de equipamentos como uma distração frequente para os enfermeiros ${ }^{(13)}$. Apesar dos ruídos sonoros dos equipamentos provocarem diminuição na concentração dos profissionais, vale lembrar que são sinais de alerta para o profissional e não devem ser desprezados.

A consulta ao prontuário e/ou prescrição médica do paciente foi o terceiro motivo de distraçóes e a segunda causa de interrupçóes. Em um estudo turco, 25,5\% das interrupçóes observadas ocorreram devido à pausa para verificar o prontuário $^{(20)}$. A consulta ao prontuário e/ou prescrição médica é necessária antes do preparo e da administração de medicamentos, no entanto, apesar da importância, durante a prática clínica da enfermagem o profissional não deve se distrair com outras informaçóes que não sejam relativas ao medicamento que está sendo preparado ou administrado.

A pausa para instrução a outros profissionais e/ou alunos foi a quarta fonte em ambas as situações de distraçóes e de interrupçóes observadas. Um estudo turco mostrou que um dos principais motivos das interrupções também foi o processo de ensino-aprendizagem de estudantes de enfermagem ${ }^{(18)}$.

Os profissionais de enfermagem foram a primeira fonte que originou as situaçóes de distraçáo e a segunda fonte de interrupção. Já a auto interrupção foi a segunda fonte mais observada nas situaçóes de interrupçáo e a auto distração a terceira fonte das distraçóes. Estudo realizado na Austrália mostrou também que a principal fonte de interrupção foi iniciada pelo próprio enfermeiro (40\%), que buscavam informaçóes sobre pacientes ou fluxo de atendimento, incluindo à realização de perguntas, instruçôes, relatar informaçốes e pedir auxílio na assistência ${ }^{(10)}$.

Outro estudo internacional identificou como uma das fontes mais frequente de interrupção a auto interrupção e os colegas de enfermagem foram responsáveis por quase metade de todas as interrupçóes $(49 \%)^{(15)}$. Dado semelhante encontrado em uma revisão integrativa brasileira apontou a auto interrupção como uma das principais fontes de interrupção ${ }^{(21)}$. Em estudo norueguês, a enfermagem também foi a maior responsável pela distração e pela interrupção no preparo e na administração de medicamentos ${ }^{(6)}$. Os enfermeiros são a última barreira de segurança no sistema de medicação, por isso devem reconhecer as distraçôes e as interrupçóes no sistema de medicação com intuito de prevenir os EM nos hospitais ${ }^{(6)}$.

Os outros profissionais, como médicos, fisioterapeutas entre outros, foram a segunda fonte das situações de distração e a terceira fonte de interrupçáo. Estudo brasileiro realizado em UTI identificou outros profissionais como terceira fonte mais frequente de interrupção $(16,5 \%)^{(17)}$. Já noutro estudo brasileiro a percepção unânime dos entrevistados foi de que a categoria profissional médica é a que mais gera as situaçóes de distraçóes e interrupções ${ }^{(21)}$.

Os acompanhantes e os pacientes foram a quarta e quinta fonte, respectivamente, de ambas as situações de distraçóes e de interrupçóes. Outro estudo brasileiro identificou os pacientes e familiares como as fontes de interrupçóes com menores porcentagens, sendo os familiares responsável por apenas $0,5 \%{ }^{(17)}$. Estudo norueguês também observou que pacientes, família, médicos, secretários e a auto distração são as fontes menos comuns ${ }^{(6)}$. Mesmo sendo a fonte menor de distração e de interrupção é importante conscientizar os pacientes e os familiares/acompanhantes sobre os riscos das distraçóes e das interrupçóes.

As situações de distrações e de interrupçóes neste estudo ocorreram principalmente durante o preparo dos medicamentos e os motivos ou causas se apresentaram 
intimamente interligadas. Em estudo conduzido na Austrália a maior parte das interrupçóes também ocorreu durante o preparo de medicamentos (73,3\%), sendo $26,7 \%$ ocorreu na administração ${ }^{(10)}$. As interrupçôes também afetaram a preparação de medicamentos intravenosos em um estudo na Noruega $^{(6)}$.

Neste estudo a falta de medicamentos foi a quinta causa de interrupção e a falta de material foi a sétima causa. Estudo canadense observou que as falhas do sistema, incluindo a falta de material foram a segunda fonte de interrupçóes durante o preparo dos medicamentos ${ }^{(19)}$. O enfermeiro é o profissional responsável pela delegação das açóes e do planejamento do cuidado, da previsão e da provisão de recursos materiais e humanos, da capacitação da equipe de enfermagem, visando sempre a melhoria e concretização do cuidado ao paciente ${ }^{(22)}$. Diante disso, o enfermeiro supervisor juntamente com a direção hospitalar deve atentar para a falta de materiais e/ou medicamentos, e principalmente promoverem açóes para o abastecimento favorável desses insumos com intuito de criar um ambiente adequado e seguro.

O uso dos telefones institucional e pessoal (celular) foram fontes importantes de interrupção, oitava e nona causas, respectivamente. Outros estudos também encontraram como principais causas de distração e de interrupção o uso de celular $^{(11,21,22)}$. Estudo realizado em um hospital escola, com o objetivo de investigar a percepção dos enfermeiros quanto as interrupçóes durante a dinâmica de trabalho, identificou como principal fonte o toque de telefone, que foi apontado como uma interrupção evitável ${ }^{(11)}$. Além dos celulares serem causa de distração e de interrupção, um estudo brasileiro realizado em uma UTI de um hospital apontou que os celulares podem propagar e atuar na disseminação de microrganismos multirresistentes, propiciando a contaminação dos pacientes ${ }^{(22)}$. Assim, é necessário desenvolver normas e estratégias para alertar os profissionais sobre o uso do celular no preparo e na administração de medicamentos. A sensibilização dos profissionais sobre os riscos deste comportamento é fator crítico de sucesso para a mudança do mesmo.

Os resultados deste estudo mostraram que distraçóes e interrupçóes são eventos presentes durante o preparo e a administração de medicamentos. Tais eventos impactam diretamente e negativamente na prática clínica da enfermagem, pois interfere na segurança do paciente e na qualidade do ambiente de trabalho da equipe multiprofissional. Por isso, é necessária uma sensibilização dos profissionais de saúde e da liderança das instituiçóes hospitalares sobre as distraçóes e as interrupçóes para que se possam instituir estratégias de superação destes eventos.

As estratégias devem ser voltadas para toda a equipe, direcionando a gestáo dos eventos de distraçóes e de interrupçóes para que haja melhor planejamento da assistência, prevenção e mitigação de danos aos pacientes ${ }^{(23)}$.
As principais estratégias descritas na literatura internacional para superação das distraçóes e das interrupçóes são a definição de uma zona de nenhuma interrupção (No Interruption Zone) ou salas de medicação separadas, os registros médicos eletrônicos durante a preparação de medicação e a dupla checagem ${ }^{(12)}$. Um estudo brasileiro mostrou que além de não se ter estratégias de minimizaçáo de distrações e interrupçóes no hospital estudado, não havia mecanismo efetivo de cobrança para o cumprimento de normas específicas como a restrição do uso do celular por todos os colaboradores ${ }^{(23)}$.

\section{CONCLUSÃO}

No presente estudo, identificou-se que as situaçóes de distraçóes e de interrupçóes no preparo e na administração de medicamentos são eventos presentes na prática clínica da enfermagem. Tais eventos interferem diretamente na segurança do paciente e na qualidade do ambiente de trabalho, sendo, portanto, pontos importantes de se discutir desde a formação dos profissionais de enfermagem e nas açôes de educação continuada e permanente dos profissionais de saúde. Essa temática também deve fazer parte da pauta de interesse da liderança das instituiçóes, para que se abordem dentro do planejamento estratégico das instituiçôes de saúde, açôes de minimização de distraçôes e de interrupçôes durante o processo de preparo e de administraçáo de medicamentos e demais atividades da prática clínica da enfermagem e equipe multiprofissional.

Assim, os estudos sobre a ocorrência de distrações e de interrupçóes é de extrema relevância na construção de uma cultura de segurança positiva nas organizaçóes de saúde visando a redução de dano aos pacientes assistidos. As estratégias de superação devem ser discutidas com toda a equipe e posteriormente padronizadas pela liderança da instituição, no sentido de se obter legitimidade destas intervençóes para maximizar a segurança do paciente.

A principal dificuldade do estudo refere-se à náo observação de todos os profissionais que aceitaram participar da pesquisa, devido à rotatividade da equipe. Como limitaçóes aponta-se a coleta de dados ter se restringido a plantóes diurnos, e as observaçóes terem ocorrido somente durante os horários padronizados para a realização dos medicamentos. Dessa forma, o quantitativo e a rapidez com que as distraçóes e as interrupçóes aconteciam podem ter implicado em um menor registro dos eventos observados. Em contrapartida, o estudo contribui com a elucidação de distraçóes e interrupçóes no âmbito do processo de preparo e administração de medicamentos em unidades de internação médico-cirúrgica, sinalizando a necessidade de se discutir a ocorrência destes eventos desde a formaçáo dos profissionais e no cotidiano de trabalho dos profissionais. 
A gravação das açóes para observação posterior em próximos estudos é uma estratégia que proporcionará mais fidedignidade do quantitativo de distraçôes e de interrupçóes. Por fim, recomenda-se a realizaçáo de outros estudos para aprofundamento da temática em diferentes setores e instituiçôes, bem como estudos que avaliem as estratégias de minimização destes eventos.

\section{REFERÊNCIAS}

1. Institute of Medicine. To err is human: building a safer health system. [Internet]. Washington (DC): National Academies Press; 2000. [acesso em: 7 out. 2017]. Disponível em: http://www.nationalacademies.org/ hmd/ /media/Files/Report\%20Files/1999/To-Err-isHuman/To\%20Err\%20is\%20Human\%201999\%20 \%20report\%20brief.pdf.

2. Brasil. Ministério da Saúde. Resolução no 36, de 25 de julho de 2013. Institui açôes para a segurança do paciente em serviços de saúde e dá outras providências. [Internet]. Diário Oficial [da União], Brasília (DF); 2013. [acesso em: 7 out. 2017]. Disponível em: http://bvsms.saude.gov.br/bvs/saudelegis/anvisa/2013/ rdc0036 2507 2013.html.

3. World Health Organization. Medication Without Harm: WHO's Third Global Patient Safety Challenge. [Internet]. Geneva, Switzerland: WHO; 2017. [acesso em: 7 out. 2017]. Disponível em: http://www.who.int/ patientsafety/medication-safety/en/.

4. World Health Organization. World Alliance for Patient Safety International Classification for Patient Safety (ICPS). [Internet]. Geneva, Switzerland: WHO; 2011. [acesso em: 8 fev. 2019]. Disponível em: http://www. who.int/patientsafety/taxonomy/en/.

5. Alteren J, Hermstad M, White J, Jordan S. Conflicting priorities: observation of medicine administration. J Clin Nurs [Internet]. 2018 [acesso em: 7 fev. 2019];27(19-20):3613-21. Disponível em: https:// www.researchgate.net/publication/325232687 Conflicting priorities Observation of medicine administration. https://doi.org/10.1111/jocn.14518.

6. Jacobsen TF, Mussi MM, Silveira MPT. Análise de erros de prescrição em um hospital da Região Sul do Brasil. Rev Bras Farm Hosp Serv Saúde São Paulo [Internet]. 2015 [acesso em: 7 fev. 2019];6(3):23-6. Disponível em: http://www.sbrafh.org.br/v1/publicl artigos/2015060304000800BR.pdf.

7. Bucknall T, Fossum M, Hutchinson AM, Botti M, Considine J, Dunning T, et al. Nurses' decision-making, practices and perceptions of patient involvement in medication administration in an acute hospital setting. J Adv Nurs [Internet]. 2019 [acesso em: 9 fev. 2019];75(6):1316-27. Disponível em: https:// onlinelibrary.wiley.com/doi/abs/10.1111/jan.13963. https://doi.org/10.1111/jan.13963.

8. Edwards S, Axe S. The 10'R's of safe multidisciplinary drug administration. Nurse Prescribing [Internet]. 2015 [acesso em: 9 fev. 2019];13(8):398-406. 9p. Disponível em: https:/www.magonlinelibrary.com/ doi/abs/10.12968/npre.2015.13.8.398. https://doi. org/10.12968/npre.2015.13.8.398.

9. Schroers G. Characteristics of interruptions during medication administration: An integrative review of direct observational studies. J Clin Nurs [Internet]. 2018 [acesso em: 9 fev. 2019];27(19-20):3462-71. Disponível em: https://www.researchgate.net/publication/326002751 Characteristics of Interruptions During Medication AdministrationAn Integrative Review of Direct Observational Studies. $\quad$ https://doi.org/10.1111/ jocn.14587.

10. Johnson M, Sanchez P, Langdon R, Manias E, LevettJones T, Weidemann G, et al. The impact of interruptions on medication errors in hospitals: an observational study of nurses. J Nurs Manag [Internet]. 2017 [acesso em: 9 fev. 2019];25(7):498-507. Disponível em: https:// onlinelibrary.wiley.com/doi/full/10.1111/jonm.12486. https://doi.org/10.1111/jonm.12486.

11. Sassaki RL, Perroca MG. Interrupçóes eseus efeitos sobrea dinâmica de trabalho do enfermeiro. Rev Gaúcha Enferm [Internet]. 2017 [acesso em: 9 fev. 2019];38(2):1-8. Disponível em: http://www.scielo.br/scielo.php? $\underline{\text { script }=\text { sci } \text { arttext } \& \text { pid }=S 198314472017000200423 \& \text { L }}$


1447.2017.02.67284.

12. Bower R, Jackson C, Manning JC. Interruptions and medication administration in critical care. British Association of Critical Care Nurses [Internet]. 2015 [acesso em: 15 nov. 2017];20(4):183-95. Disponível em: https://www.ncbi.nlm.nih.gov/pubmed/26084432. http://dx.doi.org/10.1111/nicc.12185.

13. Kurtz SL. Measuring and accounting for the Hawtone effect during a direct overt observational study of intensive care unit nurses. American Journal of Infection Control [Internet]. 2017 [acesso em: 11 fev. 2019];45(9):995-1000. Disponível em: https://www.sciencedirect.com/ science/article/pii/S0196655317302699. https://doi. org/10.1016/j.ajic.2017.03.022.

14. Souza AMN, Teixeira ER. Perfil sociodemográfico da equipe de enfermagem do ambulatório de um hospital universitário. Rev Enferm UFPE On Line. [Internet]. 2015 [acesso em: 15 nov. 2017];9(Supl.3):7547-55. Disponível em: https://periodicos.ufpe.br/revistas/ revistaenfermagem/article/view/10493. org/10.5205/reuol.7049-61452-1-ED.0903supl201507. 
15. Huckels-Baumgart $S$, Niederberger $M$, Manser $T$, Meier CR, Meyer-Massetti C. A combined intervention to reduce interruptions during medication preparation and double-checking: a pilot-study evaluating the impact of staff training and safety vests. Journal of Nursing Management [Internet]. Oct. 2017 [acesso em: 10 dez. 2017];25(7):539-48. Disponível em: http:// onlinelibrary.wiley.com/doi/10.1111/jonm.12491/full. https://doi.org/10.1111/jonm.12491.

16. Esqué Ruiz MT, Moretones Suñol MG, Rodríguez Miguélez JM, Sánchez Ortiz E, Izco Urroz M, Lamo Camino M, et al. Medication errors in a neonatal unit: One of the main adverse events. Anales de Pediatría [Internet]. 2016 [acesso em: 10 dez. 2017]; 84(4):211-17. Disponível em: https://www.ncbi.nlm.nih.gov/pubmed/26520488. https://doi.org/10.1016/j.anpedi.2015.09.009.

17. Prates DO, Silva AEBC. Interrupçóes de atividades vivenciadas por profissionais de enfermagem em unidade de terapia intensiva. Rev Latino-Am Enferm [Internet] 2016. [acesso em: $10 \mathrm{dez}$. 2017];24:e2802. Disponível em: $\quad$ http://www.scielo.br/scielo.php?script=sci arttext\&pid=S0104-11692016000100413\&lng=pt\&tl ng=pt. https://doi.org/10.1590/1518-8345.0997.2802.

18. Duruk N, Zencir G, Eses I. Interruption of the medication preparation process and an examination of factors causing interruptions. Journal of Nursing Management [Internet] 2016. [acesso em: $10 \mathrm{dez}$. 2017];24:376-83. Disponível em: http://onlinelibrary. wiley.com/doi/10.1111/jonm.12331/abstract. https:// doi.org/10.1111/jonm.12331.

19. Biron $\mathrm{AD}$, Lavoie-Tremblay $\mathrm{M}$, Loiselle CG. Characteristics of Work Interruptions During Medication Administration. Journal of Nursing Scholarship
[Internet]. 2009 [acesso em: 10 dez. 2017];41(4):330-36. Disponível em: http://onlinelibrary.wiley.com/ doi/10.1111/j.1547-5069.2009.01300.x/epdf. https:// doi.org/10.1111/j.1547-5069.2009.01300.x.

20. Bogo PC, Bernardino E, Castilho V, Cruz EDA. The nurse in the management of materials in teaching hospitals. Rev Esc Enferm USP [Internet]. 2015 [acesso em: 20 fev. 2018]; 49(4):632-39. Disponível em: http://www.scielo.br/pdf/reeusp/v49n4/0080-6234reeusp-49-04-0632.pdf. http://dx.doi.org/10.1590/ S0080-623420150000400014.

21. Ribeiro HCTC, Rodrigues TM, Teles SAF, Pereira RC, Silva LLT, Mata LRF. Distrações e interrupçóes em sala cirúrgica: percepção de profissionais de enfermagem. Esc Anna Nery [Internet]. 2018 [acesso em: 13 fev. 2019];22(4). Disponível em: http://www. scielo.br/scielo.php?script $=$ sci $\operatorname{arttext\& pid}=S 1414-$ 814520180004002108lng=en. $\quad \underline{\text { http://dx.doi. }}$ org/10.1590/2177-9465-EAN-2018-0042.

22. Reis ER, Silva W, Carvalho EV, Filho AC; Braz MR. Contaminação de telefones celulares da equipe multiprofissional em uma unidade de terapia intensiva. Saber Digital [Internet]. 2015 [acesso em: 20 fev. 2018];8(1):68-83. Disponível em: $\quad$ https://pdfs.semanticscholar.org/445d/ af20e6291c3a4e319020ae96c676eb848c23.pdf.

23. Monteiro C, Avelar AFM, Pedreira MLG. Interrupções de atividades de enfermeiros e a segurança do paciente: revisão integrativa da literatura. Rev Latino-Am Enferm [Internet] 2015 [acesso em: 20 fev. 2018];23(1):169-79. Disponível em: http://www.revistas.usp.br/rlae/ article/view/100054. https://doi.org/10.1590/0104$\underline{1169.0251 .2539}$. 